\title{
Familial clustering of leprosy patients in an Israeli village
}

\author{
D A BARREYRO*, M BARAS, PAMELA SQUIRES, \\ MARCIA WALERSTEIN, YAIR YODFAT \& L LEVY \\ Departments of Comparative Medicine, Family Medicine and \\ Medical Ecology, Hebrew University - Hadassah Medical School \\ Jerusalem, Israel
}

Received for publication 22 March 1982

Summary In an Israeli community of immigrants from Kurdistan, with a leprosy prevalence of 3.2 per 100 , the leprosy patients were found to be clustered in a very few sibships.

\section{Introduction}

That leprosy patients may be found in intrafamilial clusters - that is, that patients are found in multi-patient households more frequently than would be predicted by chance - is accepted as fact, and has often been assumed in the design of leprosy-control programmes. Yet, limiting case-finding activities in leprosy-endemic areas to the families of leprosy patients would fail to reveal the large majority of leprosy patients. A study in an area of south India with prevalence of leprosy of 21 per 1,000 found $^{1}$ that, although $8 \%$ of all families included leprosy patients, the $16 \%$ of affected families that included more than one patient accounted for only $30 \%$ of all patients. In an area of somewhat lower prevalence of leprosy $(6.6$ per 1,000$)$ in central India, it was found ${ }^{2}$ that $4 \%$ of all families included leprosy patients; the $9 \%$ of affected families that contained more than one patient accounted for only $18 \%$ of patients. No comparable studies have been reported from areas non-endemic for leprosy. Yet the results of such studies could have important implications for the design of leprosy-control activities in those areas.

An opportunity to examine the distribution of leprosy in a community in an area of low prevalence of leprosy was afforded by the presence at one time

* Submitted in partial fulfilment of the requirements for the M.P.H., Hebrew University Hadassah School of Public Health and Community Medicine.

0305-7518/82/053277+06\$01.00 C British Leprosy Relief Association 
or another in a small immigrant community near Jerusalem of a number of leprosy patients. This study has revealed unmistakable clustering of leprosy patients among intrafamilial contacts, and particularly within sibships.

\section{Materials and methods}

In 1951, Jews from four contiguous areas of Iraqi Kurdistan emigrated to Israel, and, during the next few years, a number of them settled together in Kfar A, a small cooperative farming community ('moshav') in the Judean Hills, about $45 \mathrm{~km}$ south-west of Jerusalem. The surviving settlers and their adult (more than 25 years of age) descendants now number about 250, about 180 of whom presently reside in the community, divided among 81 households.

Upon arrival in Israel, the immigrants were temporarily housed in a reception centre, at which a number of medical procedures, including examination of the skin for the presence of lesions suggesting leprosy, were carried out. The immigrants suspected of having leprosy were subsequently examined by a dermatologist, lesions were biopsied, and the diagnosis of leprosy was confirmed or denied on the basis of histopathologic evidence. Among the immigrants who settled in Kfar A, 12 cases of leprosy were detected. Two additional leprosy patients were later recognized among the original settlers. In Table 1, the 14 patients are listed, together with the year of birth, year of diagnosis and type of leprosy, all obtained from the Leprosy Register of the Ministry of Health of the State of Israel. Patients were classified largely according to the Madrid classification. An additional class - non-characteristic - was also employed.

Table 1. Leprosy patients in Kfar A

\begin{tabular}{lcccc}
\hline Patient & Sex & $\begin{array}{c}\text { Year of } \\
\text { birth }\end{array}$ & $\begin{array}{c}\text { Year of } \\
\text { diagnosis }\end{array}$ & Type $^{a}$ \\
\hline 1. AMO & $\mathrm{M}$ & 1915 & 1951 & $\mathrm{~L}$ \\
2. ANA & $\mathrm{F}$ & 1937 & 1951 & $\mathrm{I}$ \\
3. AYO & $\mathrm{M}$ & 1943 & 1951 & $\mathrm{I}$ \\
4. DDT & $\mathrm{F}$ & 1945 & 1952 & $\mathrm{~L}$ \\
5. DEL & $\mathrm{M}$ & 1932 & 1952 & $\mathrm{~N}$ \\
6. DES & $\mathrm{F}$ & 1947 & 1952 & $\mathrm{~T}$ \\
7. DME & $\mathrm{M}$ & 1943 & 1952 & $\mathrm{I}$ \\
8. DMI & $\mathrm{M}$ & 1943 & 1952 & $\mathrm{I}$ \\
9. DNA & $\mathrm{F}$ & 1941 & 1952 & $\mathrm{~L}$ \\
10. DPI & $\mathrm{M}$ & 1936 & 1952 & $\mathrm{~L}$ \\
11. MDA & $\mathrm{M}$ & 1941 & 1952 & $\mathrm{~N}$ \\
12. MKR & $\mathrm{F}$ & 1925 & 1952 & $\mathrm{~L}$ \\
13. MYA & $\mathrm{M}$ & 1919 & 1963 & $\mathrm{I}$ \\
14. YSH & $\mathrm{M}$ & 1888 & 1967 & $\mathrm{I}$ \\
\hline
\end{tabular}

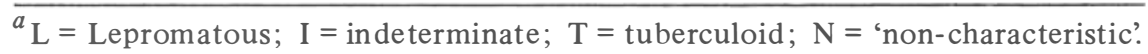


Since settling in Kfar A, the families from the four areas of Kurdistan have come to be divided among four clans, according to the specific area of origin and family ties. The four clans are here designated as the B, C, D and E clans. The B clan is the largest, including approximately $40 \%$ of the adult population of $\mathrm{K}$ far $\mathrm{A}$.

Interviews were conducted among the adult population of the community, as a result of which all of the adult members of the community were identified; extensive inquiry was made into family relationships; the residence history of every adult was recorded; and pre-existing kinship charts of the four clans were corrected and extended into earlier generations. The 14 leprosy patients were located on the kinship charts, and an analysis of the distribution of leprosy patients was carried out.

All sibships were tabulated according to clan, size of the sibship and the presence within the sibship of patients with leprosy. To analyse statistically the distribution of the leprosy patients among the sibships, the frequency distribution of sibship size was determined. Assuming the patients to be distributed randomly among the sibships, the conditional distribution of the number of patients for each size of sibship was taken to be the binomial distribution, employing the prevalence of the disease in the total population of siblings. The conditional probabilities, together with the relative frequency of sibships of every size, were used to calculate the unconditional probabilities for every possible number of patients in a sibship. Multiplying the unconditional probabilities by the total number of sibships yielded the expected number of sibships containing every number of patients. The observed distribution of patients among sibships was compared with the expected distribution by means of the $\chi^{2}$ goodness-of-fit test.

\section{Results}

Twelve of the 14 patients with leprosy were found to be members of only four sibships, all belonging to the B clan; the remaining two patients, without sibs, were also members of this clan. In addition, as shown in Fig. 1, one patient, who died in an Iraqi leprosarium, and two individuals suspected of having had leprosy, who had died in Iraq, were also members of the B clan. The two suspected leprosy patients were considered as non-patients for the purpose of this analysis.

Ninety sibships composed entirely of members above the age of 25 years were available for analysis. All of these sibships were represented in $\mathrm{Kfar} \mathrm{A}$, but many included members who had died, either in Iraq or in Israel, or who no longer resided at $\mathrm{Kfar} \mathrm{A}$. As shown in Table 2, these 90 sibships included 407 individuals, of whom 13 were leprosy patients, yielding a prevalence of 


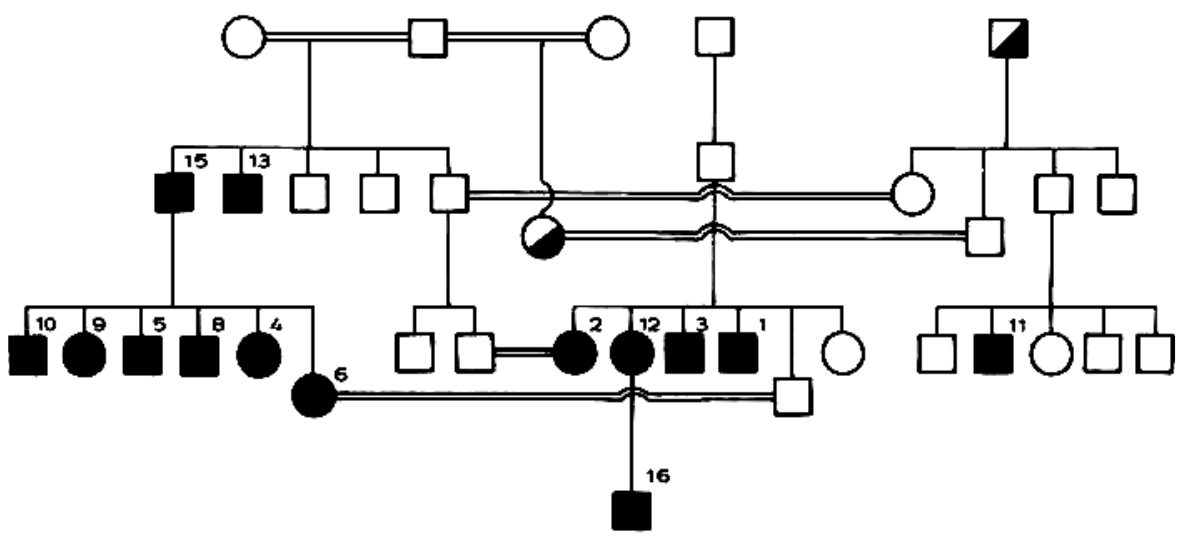

Figure 1. Simplified pedigree of a portion of the B clan, showing the patients with leprosy. Simplification was achieved by omitting those female members who were not leprosy patients, members of sibships containing leprosy patients, heads of households, or needed to demonstrate connections through marriage among the families that included leprosy patients. Fully shaded symbols represent leprosy patients whose diagnosis is not in doubt; the patients are numbered to correspond with those listed in Table 1. Patient No. 15, not included in Table 1, died in an Iraqi leprosarium. Patient No. 16, also not included in Table 1, was not included in the study because he was born in Israel within the last 25 years. The partially shaded symbols represent those suspected of leprosy in Kurdistan.

Table 2. Distribution of leprosy patients among sibships in Kfar A

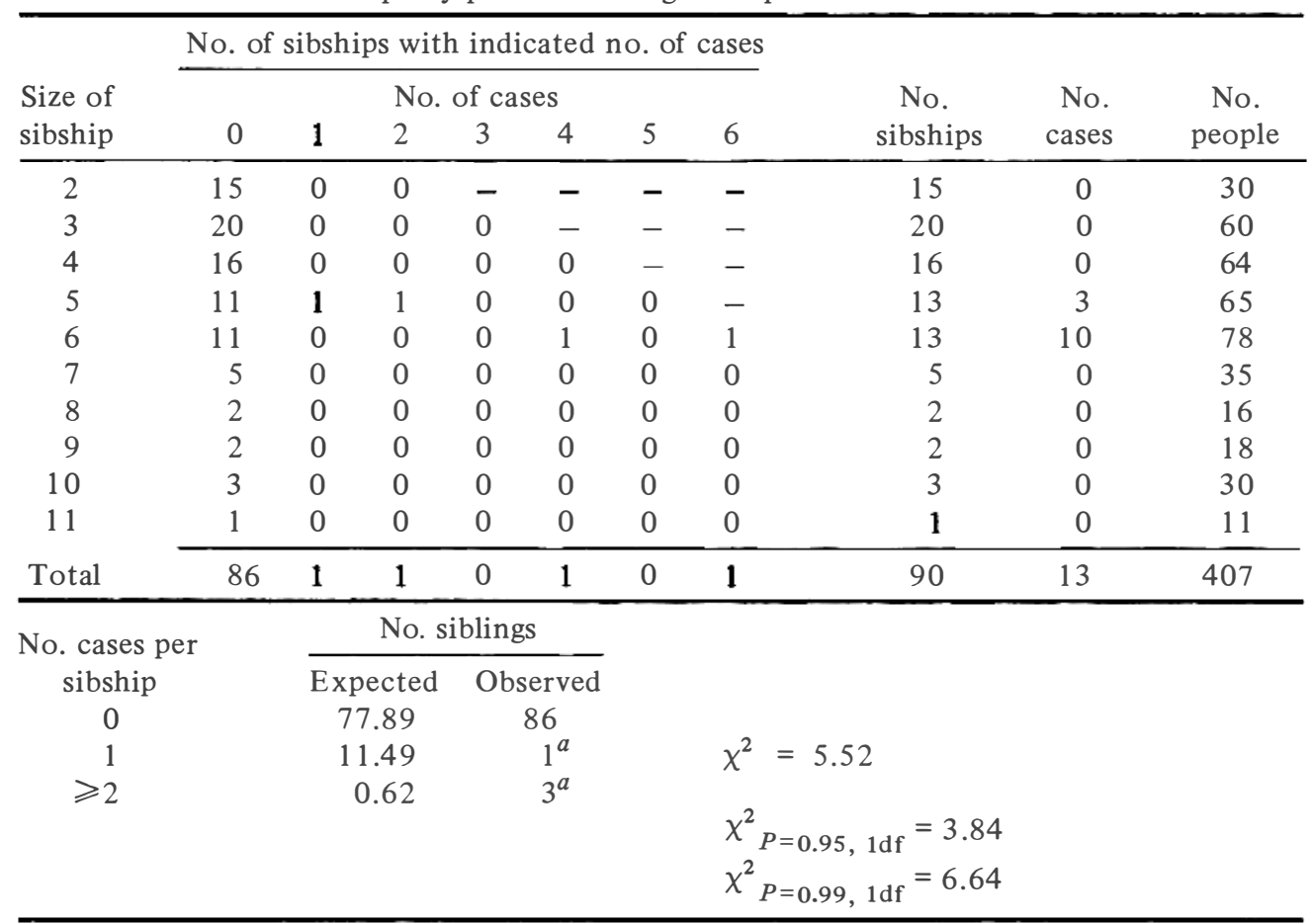

${ }^{a}$ Pooled for calculation of $\chi^{2}$ 
3.2 per 100. All 13 patients were members of four sibships that included 22 sibs. As shown in the lower panel of Table 2, the number of sibships of all sizes with no patients was significantly greater than that expected, and the number of sibships with at least one patient was significantly smaller than that expected, if the patients had been randomly distributed among the 90 sibships $(0.05<P<0.01)$.

The B clan included 38 sibships, which were composed of 169 individuals, of whom 13 were patients with leprosy (prevalence $=7.7$ per 100). Also in the B clan taken separately, the numbers of sibships with no patients and those with at least one patient were significantly different from those expected if the leprosy patients were randomly distributed among the sibships of the B clan $\left(\chi^{2}=6.67, P<0.01\right)$.

\section{Discussion}

The study of the intrafamilial distribution of leprosy patients is subject to errors and biases that derive from several sources. ${ }^{3}$ Complete ascertainment of the status of each member of the family, whether healthy or a leprosy patient, is often difficult if not impossible. Family members may have left the family home, and the status of their health may not be easily determined. Affected members may be concealed. And, especially in retrospective studies, unaffected members of the family may simply have been forgotten.

The possibility that the results of the study in Kfar A may have been influenced by ascertainment bias appears small. Emigration from Kurdistan to Israel does not appear to have been selective. Rather, the Jewish population of Iraqi Kurdistan emigrated en masse to Israel. There was simply no opportunity to examine prospective immigrants in advance of their arrival in Israel, and to exclude those suffering from certain diseases. To the contrary, one patient AMO, who was found to have leprosy in Baghdad, which served as a way-station for Kurdish Jews emigrating to Israel, and was then hospitalized in an Iraqi leprosarium - was brought from the leprosarium to Baghdad in order to rejoin his family in the final days before leaving for Israel. Another patient (No. 15 in Fig. 1) died in the Iraqi leprosarium during patient AMO's stay there.

Analysis of family data may also be difficult. ${ }^{3}$ Definitions of 'family' vary from study to study, and an individual may belong to more than one family. Corrections for age and family size are also difficult. Younger members may still be in the incubation period. And the larger the family, the greater the likelihood that it will include more than a single patient. The data derived from the study of the kinships in Kfar A appear to be free of these difficulties. Most of the individuals included in the kinship charts of Kfar A are alive; our inquiry was designed specifically for the purpose of providing kinship data; and it was possible by repeated questioning of the same and different members of the 
community to resolve points in dispute. Finally, sibships are non-overlapping; an individual can belong only to one.

Beiguelman ${ }^{4,5}$ studied the distribution of leprosy cases among sibships in an area of Sao Paulo State, Brazil, and, in fact, employed the same mathematical approach used in this paper. However, because the study was restricted to affected sibships, he was unable to derive an estimate of prevalence from his data. Therefore, Beiguelman could demonstrate only that his data were inconsistent with intrafamilial clustering of leprosy cases if leprosy prevalence were very high $(80-100$ per 1,000$)$, a very unlikely figure, but were entirely consistent with intrafamilial clustering if the prevalence were as low as 3 per 1,000 , an estimate based on other data available to him.

Review of the literature has revealed only two articles in which are presented large kinships including unaffected as well as affected sibships, that can be subjected to analysis of the frequency of leprosy cases in sibships, as we have done with the data from Kfar A. The first ${ }^{6}$ presented a large kinship, constructed from the records of a leprosarium in New Brunswick, Canada, which included 157 siblings, among whom were 78 patients with leprosy. Analysis of the sibships of this kinship demonstrates familial clustering of the leprosy patients $\left(\chi^{2}=13.00, P<0.01\right)$. The second ${ }^{7}$ presented a somewhat smaller kinship constructed from the records of the Public Health Service Hospital, Carville, Louisiana. This kinship included 41 people, among them 16 patients, distributed among 13 sibships. Familial clustering of the leprosy patients of this kinship is only suggested by these data. Interpretation of the data from these two studies requires some caution. One cannot assess the completeness of the information presented in the two kinship charts. One may well suspect them of inaccuracies, however, based as they are on the retrospective study of information that had undoubtedly been assembled for another purpose.

Having established familial clustering of the leprosy patients of Kfar A, of what significance is this finding? The two published studies ${ }^{1,2}$ of the familial distribution of leprosy patients were carried out in areas of relatively high prevalence, in which opportunities for infection by Mycobacterium leprae are not restricted to the family. But as has already been shown, multi-case families accounted for only a small minority of leprosy patients in the two areas studied. In Kfar A, on the other hand, the sources of M. leprae infection appear to have been limited both in time and number. Responsibility for case follow-up as well as for case-finding is centralized in the Ministry of Health, and all patients are seen in a single, free, Ministry-operated clinic in Jerusalem. Because they were brought under treatment as soon as they were detected, it appears likely that most of the infectious patients in Kfar A were rendered non-infectious by treatment as early as 30 years ago. The prevalence of leprosy in Israel is smaller than 0.1 per 1,000 (fewer than 250 living registered patients in a population greater than 2,500,000); thus, source-cases are few indeed, and the risk of 
infection by $M$. leprae must be limited to those in close (household) contact with one of the few infectious patients. In fact, the one leprosy patient among the Israeli-born members of the community detected thus far (patient No. 16 in Fig. 1) is the son of one of the 14 patients.

As a consequence, both in Israel and in other developed countries into which leprosy patients have immigrated, it appears justified to restrict casefinding activities to the members of the affected families. In addition, it now appears possible to consider a programme of targeted chemoprophylaxis. Programmes of chemoprophylaxis employing dapsone or acedapsone may be too expensive to be considered in developing countries in which leprosy is endemic. The cost of such programmes in a developed country is not great, however, especially if the chemoprophylaxis can be limited to those most at risk of developing the disease. In Kfar A, chemoprophylaxis could be limited to members of the B clan, and even more narrowly to those of the B clan whose residence history includes residence with a leprosy patient.

\section{Acknowledgement}

This work was supported in part by the Immunology of Leprosy (IMMLEP) component of the UNDP/World Bank/WHO Special Programme for Research and Training in Tropical Diseases, and by the Leprosy Unit of the World Health Organization.

\section{References}

1 Noordeen SK, Mohamed Ali P. A study of 579 families having multiple cases of leprosy. Lepr India, 1964; 36: 176-81.

2 Sharma VK. The epidemiologic significance of leprosy within the household. Int J Lepr, 1968; 36: 1-16.

3 Fine PEM. Immunogenetics of susceptibility to leprosy, tuberculosis and leishmaniasis: an epidemiological perspective. Int J Lepr, 1981; 49, 437-54.

4 Beiguelman B, Dall'Aglio FF, Da Silva E. Analise de recorrencia familial de lepra. Rev Paul Med, 1968; 72: 105-10.

5 Beiguelman B. An appraisal of genetic studies on leprosy. Acta Genet Med Gemellol, 1972;21: 21-52.

6 Aycock WL, McKinley EB. The roles of family susceptibility and contagion in the epidemiology of leprosy. Int J Lepr, 1938; 6: 169-84.

7 Aycock WL. Family susceptibility as a factor in the propagation of leprosy in North America. Int J Lepr, 1940; 8: 137-50. 